\title{
Mapping the Dynamics of Winter Wheat in the North China Plain from Dense Landsat Time Series (1999 to 2019)
}

\author{
Wenmin Zhang ${ }^{1,2}$, Martin Brandt ${ }^{3}$, Alexander V. Prishchepov ${ }^{3} \mathbb{D}$, Zhaofu Li ${ }^{4} \mathbb{D}$, Chunguang Lyu $^{5, *}$ \\ and Rasmus Fensholt ${ }^{3}$ (i)
}

1 School of Geography, Nanjing Normal University, Nanjing 210023, China; 90705@njnu.edu.cn

2 Key Laboratory of Virtual Geographic Environment, Nanjing Normal University, Ministry of Education, Nanjing 210023, China

3 Department of Geosciences and Natural Resource Management (IGN), University of Copenhagen, 1350 Copenhagen, Denmark; mabr@ign.ku.dk (M.B.); alpr@ign.ku.dk (A.V.P.); rf@ign.ku.dk (R.F.)

4 College of Resources and Environmental Sciences, Nanjing Agricultural University, Nanjing 210095, China; lizhaofu@njau.edu.cn

5 Shandong Provincial Key Laboratory of Water and Soil Conservation and Environmental Protection, College of Resources and Environment, Linyi University, Linyi 276005, China

* Correspondence: lvchunguang@lyu.edu.cn

Citation: Zhang, W.; Brandt, M.; Prishchepov, A.V.; Li, Z.; Lyu, C.; Fensholt, R. Mapping the Dynamics of Winter Wheat in the North China Plain from Dense Landsat Time Series (1999 to 2019). Remote Sens. 2021, 13, 1170. https://doi.org/10.3390/rs 13061170

Academic Editor: Karel Charvat

Received: 3 February 2021

Accepted: 16 March 2021

Published: 19 March 2021

Publisher's Note: MDPI stays neutral with regard to jurisdictional claims in published maps and institutional affiliations.

Copyright: (c) 2021 by the authors. Licensee MDPI, Basel, Switzerland. This article is an open access article distributed under the terms and conditions of the Creative Commons Attribution (CC BY) license (https:// creativecommons.org/licenses/by/ $4.0 /)$.

\begin{abstract}
Monitoring spatio-temporal changes in winter wheat planting areas is of high importance for the evaluation of food security. This is particularly the case in China, having the world's largest population and experiencing rapid urban expansion, concurrently, it puts high pressure on food demands and the availability of arable land. The relatively high spatial resolution of Landsat is required to resolve the historical mapping of smallholder wheat fields in China. However, accurate Landsat-based mapping of winter wheat planting dynamics over recent decades have not been conducted for China, or anywhere else globally. Based on all available Landsat TM/ETM+/OLI images ( 28,826 tiles) using Google Earth Engine (GEE) cloud computing and a Random Forest machine-learning classifier, we analyzed spatio-temporal dynamics in winter wheat planting areas during 1999-2019 in the North China Plain (NCP). We applied a median value of 30-day sliding windows to fill in potential data gaps in the available Landsat images, and six EVI-based phenological features were then extracted to discriminate winter wheat from other land cover types. Reference data for training and validation were extracted from high-resolution imagery available via Google Earth $^{\mathrm{TM}}$ online mapping service, Sentinel-2 and Landsat imagery. We ran a sensitivity analysis to derive the optimal training sample class ratio $(\beta=1.8)$ accounting for the unbalanced distribution of land-cover types. We mapped winter wheat planting areas for 1999-2019 with overall accuracies ranging from $82 \%$ to $99 \%$ and the user's/producer's accuracies of winter wheat range between $90 \%$ and $99 \%$. We observed an overall increase in winter wheat planting areas of $1.42 \times 10^{6}$ ha in the NCP as compared to the year 2000, with a significant increase in the Shandong and Hebei provinces $(p<0.05)$. This result contrasts the general discourse suggesting a decline in croplands (e.g., rapid urbanization) and climate change-induced unfavorable cropping conditions in the NCP. This suggests adjustments of the winter wheat planting area over time to satisfy wheat supply in relation to food security. This study highlights the application of Landsat images through GEE in documenting spatio-temporal dynamics of winter wheat planting areas for adequate management of cropping systems and assessing food security in China.
\end{abstract}

Keywords: winter wheat; Landsat; time series; change detection; cloud computation; machine learning; North China Plain

\section{Introduction}

Global population growth leads to increasing demand for agricultural crops, which is expected to continue in the coming decades [1]. Therefore, global- and regional-scale agricultural monitoring systems are needed to provide accurate information about agricultural 
production to actors and decision-makers for improved agricultural production planning. Land-cover transformations related to agricultural expansion and land abandonment have accelerated over the past decades in many parts of the world [2,3]. Moreover, climate change-induced droughts, extreme rainfall and heatwaves may force farmers to adjust crop systems in adaptation to climate change [4]. Wheat is one of the major grain crops with a projected global production of $\sim 765$ million metric tons in 2019 [5] and feeds 2.5 billion people across the globe [6]. However, winter wheat planting areas are often managed by smallholder farmers and are patchy in nature, thereby hampering quantification and continuous monitoring of yield estimates needed to ensure food security $[7,8]$. About two-thirds of the developing world's 3 billion rural people live in about 475 million small farm households, working on land plots smaller than 2 hectares and in China, nearly 98 percent of farmers belong to small farm households [9].

Knowledge about spatial and temporal changes in winter wheat extent in China is crucial as China has the world's largest population and has undergone profound urbanization and economic growth in recent decades. To satisfy food demands, China produces large amounts of wheat but also depends on wheat imports. At the same time, rapid urbanization and economic development reduce the availability of arable land suited for wheat production. For instance, studies show that agricultural land in China was reduced by 3.31 million ha from 1992 to 2015 due to urban expansion [10]. Additionally, to satisfy wheat demand and changing diets, there have been documented a shift from rice to wheat and maize production [11]. Climate change is another driver that significantly affects the production of crops both globally and in China $[12,13]$. Therefore, the extent and dynamics of croplands, as well as the extent of winter wheat for a single or selected year, have been studied. However, no studies so far have tracked the dynamics of winter wheat planting areas in China for large areas and multiple years.

Remote sensing techniques have been widely used for broad land-use/cover at the global and regional scale $[14,15]$. However, broad land-use/cover classes, such as cropland, forest, grassland, built-up area, without information on specific crops, are of little practical use for managing cropping systems. Considerable efforts have recently been made to identify crop types including winter wheat $[16,17]$, corn and soybean [18] and to predict tillage, soil carbon sequestration and soil moisture [19,20], etc., through the use of temporal reflectance composites of MODIS, Landsat, Sentinel-1/2 and the combined use of multiple data sources, e.g., fusing Landsat and Sentinel-2 data at regional and country scales [21,22]. Moreover, some studies have made use of cropping system information (e.g., crop rotation of wheatmaize) in combination with remote sensing data to detect areas of winter wheat [23]. These studies have considerably advanced the identification of crop types and contributed to more accurate estimations of crop yields, yet at a coarse spatial resolution ( $\geq 250 \mathrm{~m}$, MODIS) that cannot fully capture small-scale farming systems of winter wheat, for instance, in China. In reality, heterogeneous mosaics of different crop types often dominate agricultural lands, thus challenging an accurate quantification of specific crop species. Sentinel-2 and Worldview have offered better opportunities for the detection of crop types due to the improved spatial and temporal resolution. However, the relatively recent launch of sensors prevents temporal depth in any change analysis. Consequently, both spatial resolution and long-term records are required to identify crop types planted in small field patches to track the dynamics of winter wheat impacted by urban expansion, climate change and changes in economic incentives. Landsat data at 30-m spatial resolution available from 1984 to present provides the only satellite-based opportunity for tracking long term changes in winter wheat planting areas at a spatial resolution matching field size [24]. Still, these data have so far not been fully exploited for this purpose.

Time series of vegetation indexes, such as the normalized difference (NDVI) and enhanced vegetation index (EVI) were successfully used to capture vegetation growing cycles $[17,25]$ and distinguish different crop types including winter wheat. Several studies have mapped winter wheat based on a single image date or combined several image dates of indicators during the growing season and these studies generally relied on a priori knowledge, 
such as setting thresholds based on vegetation indices [16,26,27]. Additionally, other methods, including supervised classification, transformation-based and metric-based approaches, have been used for crop classification [28,29]. Recently, a phenology-time weighted dynamic time warping approach has successfully been applied to map wheat [30-32], and deep learning has also proved to be effective to map crop types [33]. Among these approaches, the widely used Random Forest (RF) classifier was used for the NCP mapping of the past 20 years based on dense time series of Landsat medium resolution imagery. RF was chosen here due to its robustness, computational efficiency and the ability to make use of temporal information characterizing the growth cycle of winter wheat [34-36]. Moreover, it can efficiently handle and classify winter wheat fields with a non-normal distribution of spectral reflectance and RF is embedded in GEE that facilitates such classification endeavors across space and time based on Landsat data.

In this study, we aim to detect the dynamics of winter wheat and to fill the existing gap of long-term high spatial resolution observations of winter wheat in the NCP region. Specifically, we apply Landsat-5 TM/7 ETM+/8 OLI time series to produce EVI based temporal metrics capturing the specific growing season of winter wheat. The cloud platform of GEE provides access to the archived data from an array of Earth observation satellite systems (including the Landsat sensors). GEE allows working with images in an intrinsically parallel processing way using state-of-the-art cloud-computing and storage capability was used to process thousands of Landsat images [37]. The objectives of this study are to (1) present a phenology-based approach to map winter wheat using Landsat EVI time series; (2) implement the sensitivity analysis to account for the unbalanced distribution of land-cover types; (3) map winter wheat planting areas in NCP with 30-m Landsat time-series using the developed approach; and (4) assess the dynamics of Landsat-based winter wheat areas and detect the frequency of winter wheat planted in NCP from 1999 to 2019. Such information is a prerequisite for adequate management of cropping systems and assessing food security in China and other major wheat breadbaskets of the world.

\section{Materials and Methods}

\subsection{Materials}

\subsubsection{Study Area}

The study area is located between latitude $29.36^{\circ} \mathrm{N}-42.67^{\circ} \mathrm{N}$ and longitude $110.25^{\circ} \mathrm{E}-$ $122.70^{\circ} \mathrm{E}$ and includes seven provincial-level administrative units (fine provinces and two direct-controlled municipalities) (Figure 1a): Anhui, Jiangsu, Henan, Shandong, Hebei provinces, Beijing and Tianjin municipalities. The area includes the largest agricultural area in China, with $45,696,000$ ha of croplands, of which wheat covers approximately $90 \%$. The production of winter wheat in this area corresponds to $71 \%$ of the country's total wheat production [26]. The study area is separated by the Qin Mountains and the Huai River and thus has a topography which includes mountains in the west, hills in the south, plains in the east and middle areas, and an elevation ranging from around -100 to $3500 \mathrm{~m}$ (Figure 1a). The northern part of the study area is dominated by a temperate continental monsoon and the southern part is characterized by a subtropical continental monsoon.

In general, winter wheat is sown during October-November and harvested during June-July in the following year; pheno-phases includes seeding, tillering and heading during the growing season [16]. Winter wheat is mostly planted in flat areas with a relatively lower altitude that is easy to be cultivated and managed. Rapeseed is another crop type partly planted in the winter but constitutes only a small proportion of winter crops in this area. A double cropping rotation comprised of winter wheat-summer maize is the dominant cropping system, but there are also cropping rotations including winter wheat-corn, winter wheat-peanut and fallow-spring maize/peanut. The study area also has the highest population density in China with a rapid urban expansion at the expense of cropland [38,39]. 


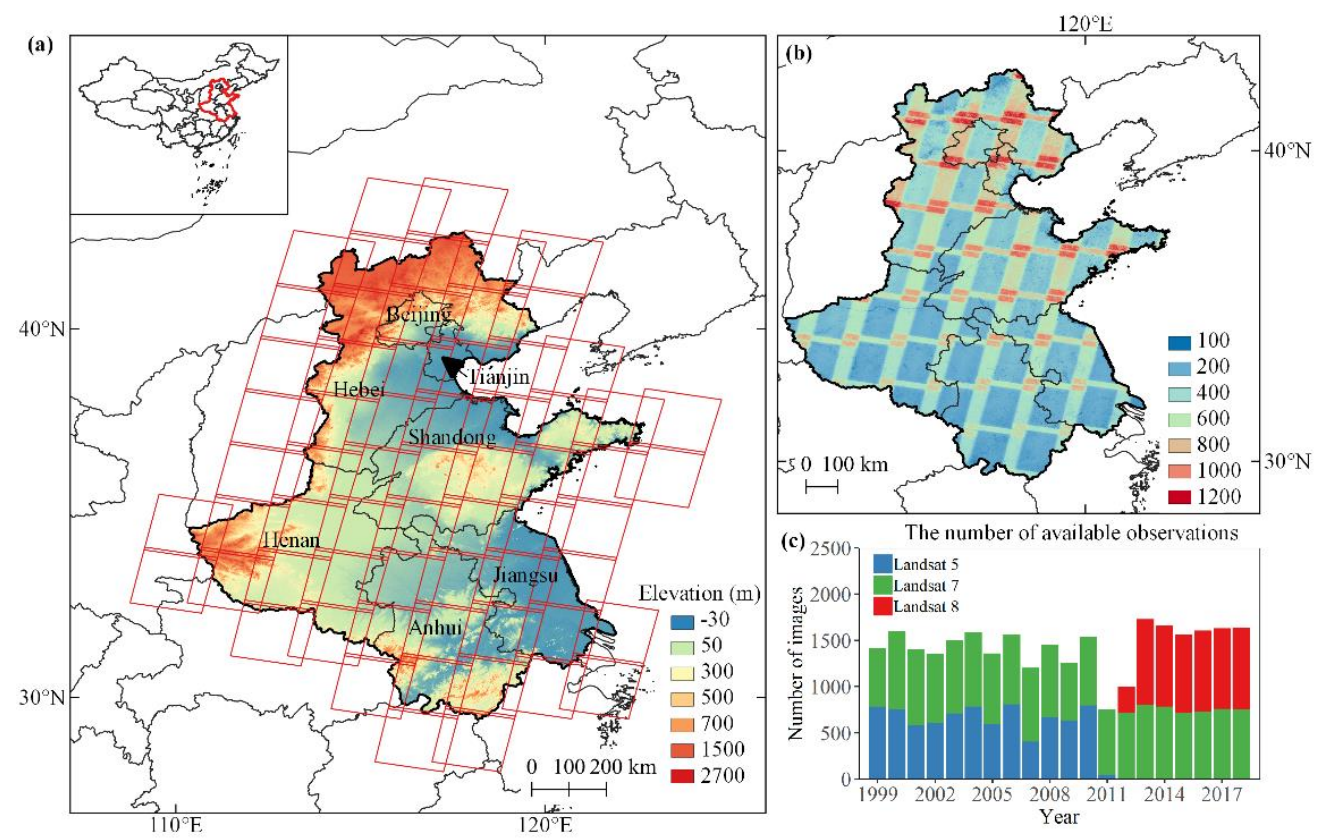

Figure 1. Location of the study area and the availability of Landsat images for 1999-2019. (a) Location of the study area and its topography; (b) the number of available Landsat images during 1999-2019 (the number of available Landsat images per growing season of winter wheat are shown in Figure S1); (c) the number of available Landsat images by sensors (Landsat-5/7/8), the year 1999 denotes the growing season covering 1999-2000 (1 October 1999-30 June 2000), etc.

\subsubsection{Landsat Data Processing}

The study area covers 64 tiles of Landsat images (Figure 1a). Landsat images used in this study including, Landsat-5 TM which spans the long period between 1984 and late 2011. Landsat-7 ETM+ is also available from the year of 1999. Landsat-8 OLI provide imagery starting from April 2013. Landsat TM/ETM+/OLI products provide the "Surface Reflectance Tier 1" products that have the highest quality imagery meeting certain radiometric and geometric requirements. They all contain 3 visible bands (blue, green and red), 1 near-infrared (VNIR) bands and 2 short-wave infrared (SWIR) bands, as well as 1-2 thermal infrared (TIR) bands. This dataset is the atmospherically corrected surface reflectance and is all available in GEE cloud platform. We used all available atmospherically corrected surface reflectance tier 1 data from Landsat-5 TM, Landsat-7 ETM+ and Landsat-8 OLI between October 1st and June 30th from 1999 to 2019. Cloud, cloud shadows, cirrus and snow /ice were masked with the CFMASK algorithm [40]. In total, 28,826 Landsat scenes were processed via the GEE platform (Figure $1 \mathrm{~b}$ ), and the spatial distribution of the number of available Landsat images for each growing season of winter wheat is shown in Figure S1 and by satellites (Landsat-5/7/8) (Figure 1c). To circumvent the impacts from potential data gaps caused by the occasional scarcity of Landsat images available, we excluded any analysis of the growing seasons spanning 2011-2012, 2012-2013, when only Landsat-5 TM and Landsat-7 ETM+ Scan Line Corrector (SLC)-off were available (Figures 1c and S1).

\subsubsection{Training/Validation Sample from Google Earth ${ }^{\mathrm{TM}}$ (GE), Sentinel-2 and Landsat}

Field observations were collected in the study area from field visits during March and April 2019. This involved recording of GPS coordinates for large and homogeneous winter wheat fields (Figure S2) to be used for analysis of corresponding Landsat image spectral signatures. We then collected training/validation sample of winter wheat fields from multiple reference image sources based on GE, Sentinel-2 and Landsat data (Figure 2). Specifically, 18,432 points were generated (keeping the minimum distance of $200 \mathrm{~m}$ ) from the 364 polygons that were randomly manually digitized from these reference data sources for 9 epochs (1999-2000, 2004-2005, 2009-2010, 2013-2014, 2014-2015, 
2015-2016, 2016-2017, 2017-2018, 2018-2019) (Table 1). The Sentinel-2 derived true-color composites (bands 4/3/2) and false-color composites (bands 8/4/3) from 2015 to 2018 were mainly used as a reference for sample collections. GE images were used as a reference prior to the year of 2005 and Landsat true and false-color composites were used as well for reference data collection. The Areas Of Interest (AOIs) were generated according to the field size/shape and reference GE images, Sentinel-2 and Landsat color composite images. The AOIs of the 9 epochs were equally distributed across the study area and the distribution of AOIs overlaid with Landsat tiles (path/row) fully covered all the land cover types analyzed.

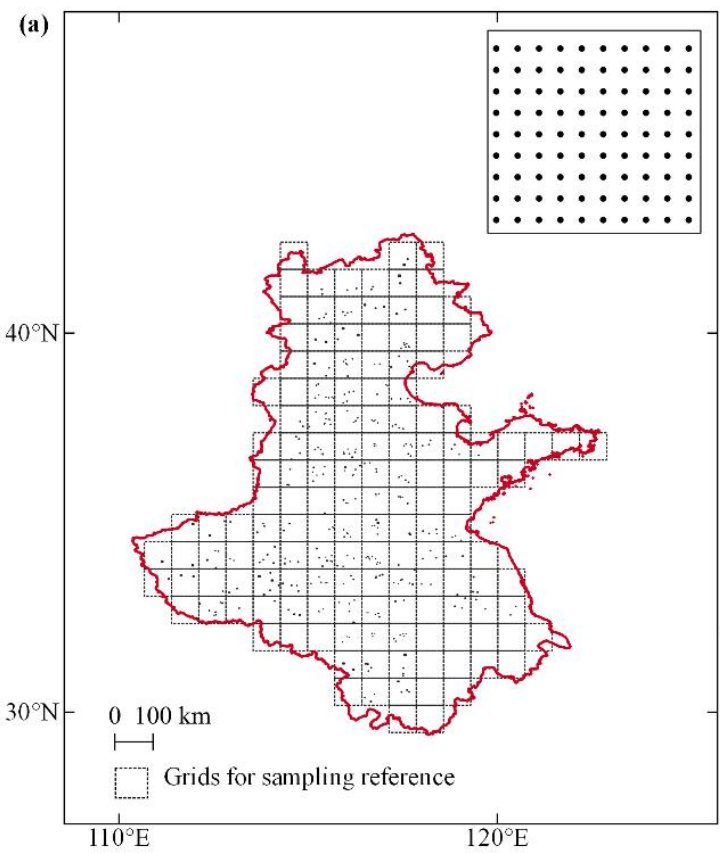

(b)

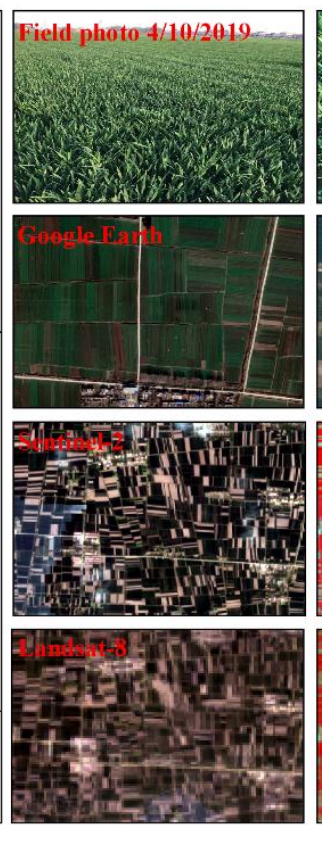

(c)

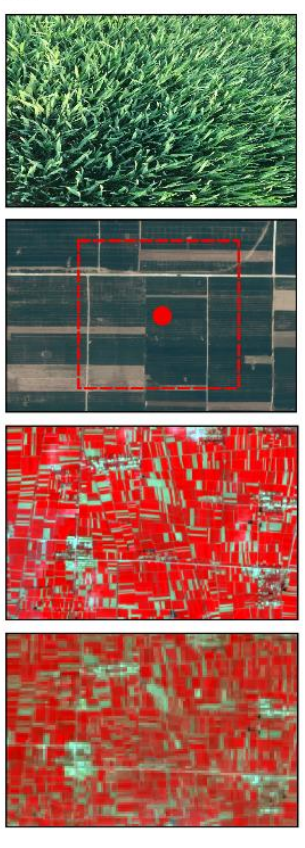

Figure 2. Training/validation sample collections. (a) Location of the areas of interest consisting of 364 polygons and the inserted polygon (upper right corner) showing the points generated with a minimum distance of $200 \mathrm{~m}$ is one of the 364 polygons. The grids for the determination of polygon locations are $80 \times 80 \mathrm{~km}$. (b,c), illustration of fieldwork records, GE, Sentinel-2, Landsat -8 true-color composite (bands 4/3/2) and false-color composite (bands $8 / 4 / 3$ ) for the training sites. The red rectangle in (c) shows a grid of $200 \times 200 \mathrm{~m}$ for one sampling point generation with imagery from GE. A field campaign has been carried out to visually interpret the winter wheat in the images (Figure S2).

Table 1. Sample of training and validation sets (pixels size $=30 \times 30 \mathrm{~m}$ ) collected from different years and their sources of reference. The variability between years in the number of classes for which reference data are provided, is determined by the ability to identify reference sample collected that depends on the availability of historical GE images (time view in GE).

\begin{tabular}{|c|c|c|c|c|c|c|c|}
\hline \multirow[b]{2}{*}{ Epoch } & \multicolumn{6}{|c|}{ Land Cover (Pixels) } & \multirow{2}{*}{$\begin{array}{c}\text { Reference } \\
\text { Sources }\end{array}$} \\
\hline & $\begin{array}{l}\text { Winter } \\
\text { Wheat }\end{array}$ & Other Crops & $\begin{array}{l}\text { Deciduous } \\
\text { Forest }\end{array}$ & $\begin{array}{c}\text { Evergreen } \\
\text { Forest }\end{array}$ & $\begin{array}{l}\text { Built-Up } \\
\text { Land }\end{array}$ & Water & \\
\hline 1999-2000 & 1547 & - & - & - & - & - & Landsat-5/7GE \\
\hline 2004-2005 & 535 & - & - & - & - & - & Landsat-5/7/GE \\
\hline 2009-2010 & 858 & - & - & - & - & - & Landsat-5/7/GE \\
\hline 2013-2014 & 1547 & - & - & - & - & - & Landsat-8/GE \\
\hline 2014-2015 & 611 & - & 903 & - & 567 & - & Landsat-8/GE \\
\hline 2015-2016 & 381 & 348 & 640 & - & 382 & 90 & Sentinel-2/GE \\
\hline 2016-2017 & 743 & 485 & 625 & 690 & 918 & 388 & Sentinel-2/GE \\
\hline 2017-2018 & 288 & 102 & 508 & 320 & 190 & 837 & Sentinel-2/ GE \\
\hline 2018-2019 & 745 & 447 & 1936 & 154 & 427 & 221 & Sentinel-2/ GE \\
\hline Total & 7255 & 1382 & 4612 & 1164 & 2484 & 1536 & \\
\hline
\end{tabular}


Apart from making use of the information from the true/false-color images of Sentinel-2, GE and Landsat to identify winter wheat and the other land-cover types, we also depended on the visual interpretation of image time-series of EVI profiles to collect referring sample. Winter wheat has two distinct seasonal peaks during the cycle from October 1st to June 30th in the following year that are easily used to separate winter wheat from other land cover types, supporting collection of winter wheat sample correctly using satellite/GE imageries. Spring/summer/other crop types mainly including maize, bean and peanut, are expected to cause the primary confusion with winter wheat. We, therefore, collected additional sample of EVI in the land-cover class of croplands (Figure S3). We also collected information on additional land cover classes that may affect the classification, including deciduous forest, evergreen forest, built-up land and water during the process of sample collections (Table 1). As this study focuses on winter wheat, we did not evaluate the other land cover types in the confusion matrixes and merged them into a class termed non-winter wheat.

\subsection{Method}

The workflow of mapping winter wheat planting areas includes four steps (Figure 3). Firstly, we extracted time series of EVI from Landsat images and used the cloud-free pixels to derive EVI based metrics that discriminate winter wheat against other land cover types. Secondly, we created training and validation sample sets using high-/medium-resolution imagery from GE online mapping service, Sentinel-2 and Landsat (Figure 2) and implemented a sensitivity analysis to derive the best ratio of training sample $(\beta)$ for an optimal balance between user's (overestimation) accuracy and producer's (underestimation) accuracy. Thirdly, we used the $\beta$-adjusted training sample to train the RF model with the input of EVI based metrics to generate winter wheat planting areas for 1999-2019. Finally, we used sample from step 2 for validation and analyzed spatio-temporal changes in winter wheat planting areas.

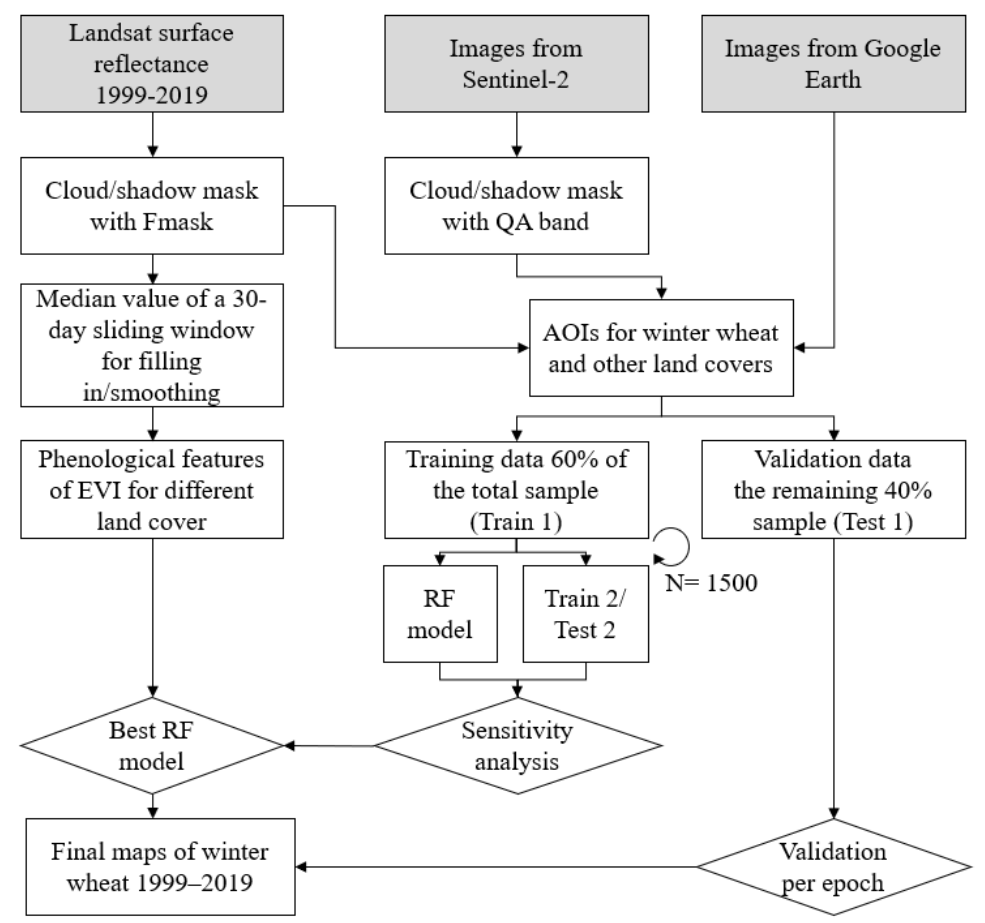

Figure 3. Flowchart showing the methods used to produce epoch/annual maps of winter wheat.

\subsubsection{Metrics Derived for Classification}

All the non-masked Landsat images were used to calculate EVI and gaps were filled in with the median value of a 30-day sliding window. At the same time, the median 
window was used to smooth the time series of EVI over each winter wheat growing season (1 October-30 June) (Figure 4). The original time series of EVI are shown in Figure S4.
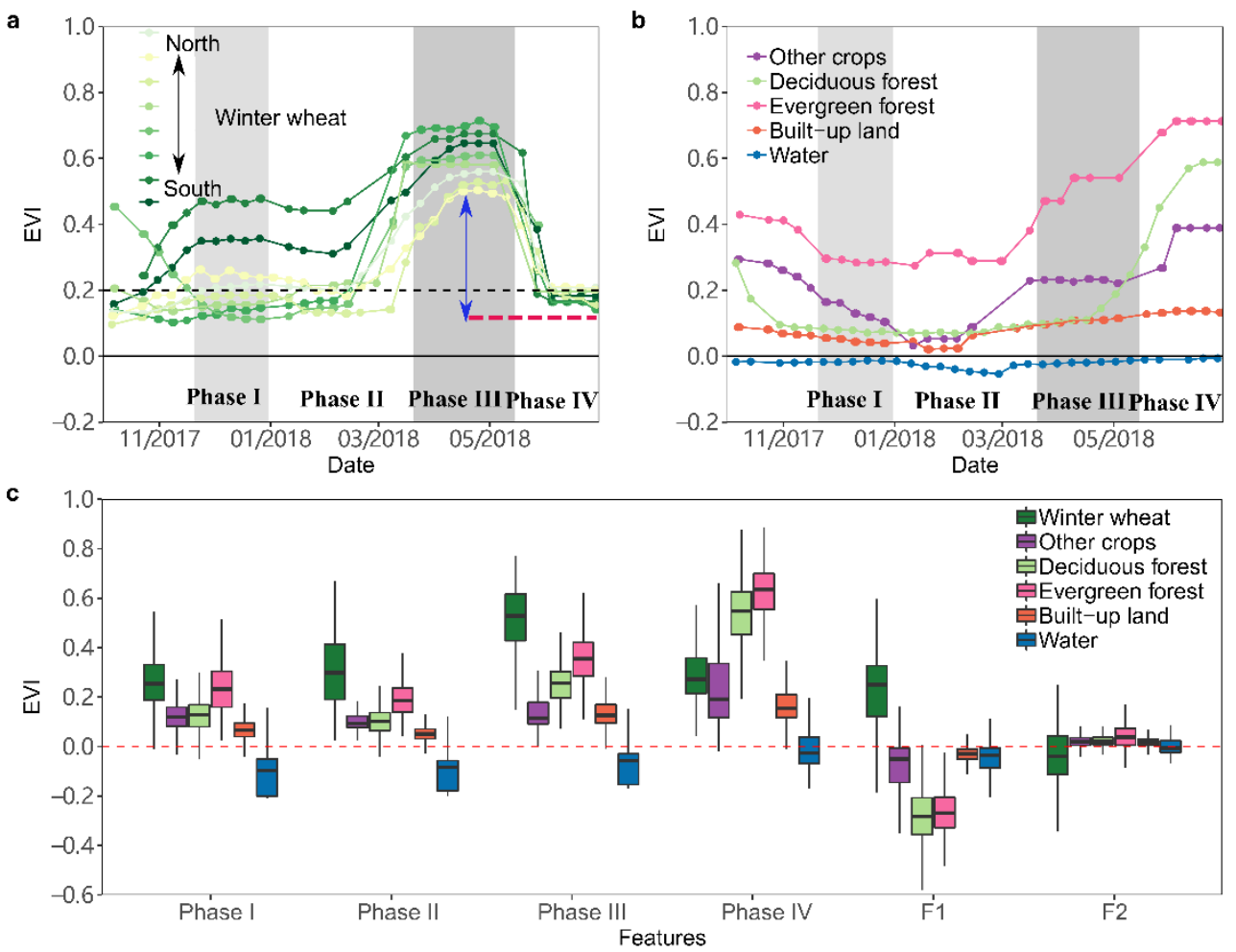

Figure 4. Phenological phases of EVI profiles for winter wheat and other land cover types. (a,b) Temporally smoothed EVI of winter wheat and other land cover types for northern to southern zones (the corresponding original EVI spectral are shown in Figure S4). Light and darker grey shadings represent the respective periods of seeding and heading of winter wheat. (c) EVI of different land cover classes represented by the six phenological metrics.

We averaged the smoothed EVI for the Phase I (20 October-31 December; covering the period of seedling and tillering), Phase II (10 January-25 February; over-wintering), Phase III (20 March-15 May or 10 April-31 May; jointing/heading) and Phase IV (20 May-30 June or 1 June-30 June; maturing) to derive four EVI based metrics that are used to classify the winter wheat against other land cover types (Figure $4 a, b)$. Two different dates for Phase III and Phase IV were applied for the northern and southern study area, defined by the transection of the latitude $34.57 \mathrm{~N}$ degree and determined by the change in winter wheat phenology (Figure 4a) from northern to southern zones. The different dates are implemented using the grids $(80 \times 80 \mathrm{~km})$ for reference samplings shown in Figure 2a. We further calculated the Feature 1 (F1) and Feature 2 (F2) as the difference in EVI average values between phase I-II and III-IV, respectively. These six image composite metrics represent the inputs for RF model training. A distinct difference between winter wheat and the other land cover is observed from several of the EVI metrics derived (Figure 4) and particularly so for the F1. The use of average EVI over a given phase has the advantage of reducing the influence from gaps in Landsat image availability.

\subsubsection{Sensitivity Analysis of Sampled Training Data}

The class distribution of the collected sample for winter wheat and non-winter wheat was unbalanced, which could potentially introduce a bias of classification with overestimation of the dominant (winter wheat) and underestimation of the rare class (non-winter wheat). To evaluate the impact of unbalanced class distribution on the accuracy, we applied a sensitivity analysis approach proposed by [35] that tests different class ratios ( $\beta$ ) to define the best ratio of training sample to find an optimal balance between user's (overestimation) 
accuracy and producer's (underestimation) accuracy. For the analysis of class ratio optimization and the final classification and accuracy assessment, a 10-fold iterative procedure was performed using the selected metrics for the RF. Initially, $60 \%(11,059)$ of the collected pixels were randomly selected as the training pixels (Train 1) and the remaining $40 \%$ (7373) were used as validation pixels (Test 1). For each iteration, a fixed number of 1500 training points (Train 2) were randomly generated from the pool of training pixels (Train 1 ) and the rest of the training pixels (Train 1) were used as a test set (Test 2). The parameter $\beta$ refers to the ratio of winter wheat and non-winter wheat pixels in the training set and was changed iteratively to approach an optimal value $\beta n$ balancing producer's and user's accuracies. The procedure started from an equal class distribution $(\beta i=1)$, which defines the number of pixels for winter wheat $(1500 /(1+\beta i))$ and non-winter wheat $(1500 * \beta i /(1+\beta i))$, and in each step $\beta i$ was increased by 0.1 until reaching a non-winter wheat-fivefold class distribution ( $\beta i=5)$ [36]. The optimal ratio of $\beta i$ was subsequently used to adjust the subsets of Train 1 and the remaining sample pixels were used as test pixels.

\subsubsection{Classification and Accuracy Assessment}

We applied a RF model to map winter wheat planting areas with Landsat EVI time series data consisting of six EVI based metrics (October-June). The RF classifier is an ensemble classifier that generates multiple decision trees and is trained using bagging, thereby enabling the trees to determine the probability of the class membership [31]. RF performs multiple criteria classifications and has the advantage of fast processing speed and is less sensitive to overfitting. We used the default GEE parameters (the number of variables per split is set to the square root of the number of input features and the fraction of input to bag per tree is 0.5 ) for RF with 100 trees to train the time series of Landsat EVI with the optimal $\beta$-adjusted Train 1 sample pixels (a total of $11,059(60 \%)$ ) (Figure 5). The remaining sample pixels (a total of $7373(40 \%)$ ) were subsequently used to validate the performance of the developed model for each epoch separately. We developed one model for the entire period of analysis with the $60 \%$ of the entire collected samples, as separate RF models for each epoch cannot be trained since the collected training data only include one land cover class (winter wheat) during the early period (e.g., the epoch for 1999-2000).

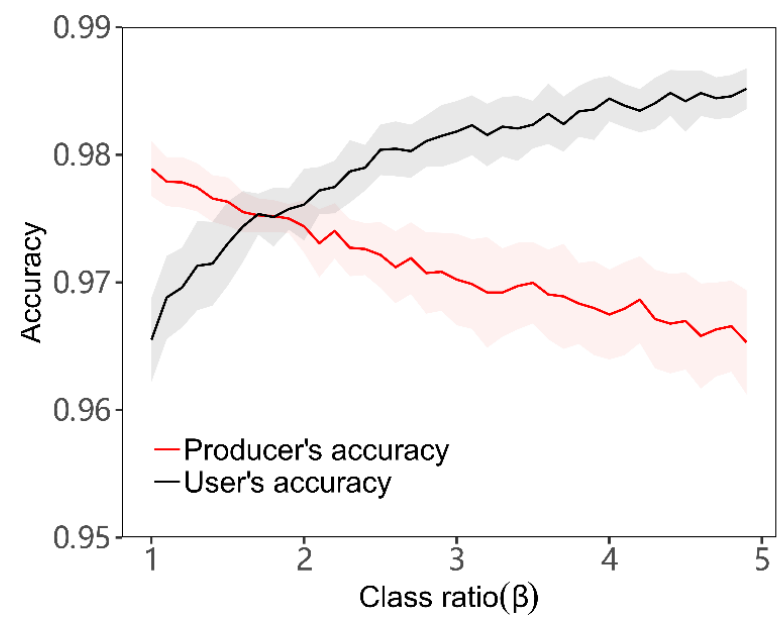

Figure 5. Estimates of the optimal class ratio $(\beta)$ that achieves a balance between user's accuracy (black line) and producer's accuracy (red line). The lines indicating the mean of the accuracies were produced from 10 -fold subsampling runs for each $\beta$. The shadings show $95 \%$ confidence intervals. An optimal ratio of $\beta=1.8$ was derived and applied for all years of classification.

The classification accuracy was estimated using contingency (confusion) matrices. We calculated the area-weighted overall accuracy, producer's and user's accuracies for the two categories of winter wheat and non-winter wheat for each year. We also calculated error- 
adjusted area estimates and the proportion of each class based on the results of accuracy assessments following state-of-the-art accuracy assessment recommendations [41].

\subsubsection{Analysis of Spatio-Temporal Patterns of Winter Wheat Planting Areas}

The years of 2011-2012 are excluded from further analyses because of limited Landsat data availability (Figures 1c and S1), whereas for the years of 1999, 2002, 2005-2007, 2009 and 2015, an uncertainty measure is estimated from the unobserved component of the maximum extent of wheat during the full period following the approach of [42]. As part of the wheat planting area in those years is potentially not taken into account (not observed), this represents a source of underestimation of the reported area. We combined the measured values of wheat planting area with an estimate of the area of unobserved but potential wheat planted area to account for this by computing the maximum wheat area extend during the entire period. The true wheat planting area will lie somewhere within this unobserved range, but the actual limits cannot be established. To characterize the spatio-temporal patterns of winter wheat planting areas in the NCP, we examined their dynamics for 1999-2019 using a linear trend analysis for the entire area and (years with insufficient Landsat data coverage were excluded from the trend analysis) at the province level (Beijing and Tianjin are excluded from this analysis as they occupy a small proportion of the winter wheat planted area across the $\mathrm{NCP}(\sim 0.62 \%)$. We then calculated the per-pixel frequency of Landsat derived winter wheat planting, which is the total occurrences of winter wheat planting from 1999 to 2019 divided by the number of years. Moreover, we assessed the changes in winter wheat planting areas by calculating the classes of stable, gain and loss of winter wheat areas for the period 2000-2019. The classes were defined accordingly: We split the entire period into two sub-periods, covering 1999-2009 and 2010-2019, respectively, and calculated the per-pixel frequency of winter wheat fields within each sub-period. Frequencies of winter wheat fields of the two sub-periods were compared and if the increase rate was above $20 \%$, the pixel was denoted as gain and if the decrease rate was lower $20 \%$, it was denoted as loss. Pixels of change frequencies in-between $20 \%$ decrease and $20 \%$ increase were denoted as stable.

\section{Results}

\subsection{Winter Wheat Area Mapping Using Landsat Time Series}

The winter wheat planting areas were mapped for the growing season of 2017-2018 (Figure 6), showing that winter wheat was mostly occurring in Henan, southern Hebei, northern Anhui, northern Jiangsu and Shandong (except the Taishan mountain areas), with an entire area coverage of $3.32( \pm 0.25) \times 10^{7}$ ha in NCP. Specifically, the Henan province has the largest area of winter wheat with $8.47 \times 10^{6}$ ha $(25.5 \%$ of the winter wheat planting areas in NCP), followed by Shandong (22.11\%), Jiangsu (20.79\%), Anhui (19.93\%), Hebei $(11.09 \%)$, Tianjin $(0.41 \%)$ and Beijing $(0.15 \%)$. Figure $6 \mathrm{~b}$ and $\mathrm{c}$ show four different subsets of the classification results representing the varying density of winter wheat and the corresponding Landsat-8 false-color composites (bands-5/4/3).

\subsection{Accuracy Assessment of Landsat-Based Winter Wheat Area Maps}

The overall accuracies of the Landsat-based classification of winter wheat planting areas ranged from 0.824 to 0.999 (Tables 2 and S1). The user's accuracies varied between 0.900 and 0.988 and the producer's accuracies between 0.940 and 0.999 , indicating that the model can accurately map winter wheat planting areas throughout all epochs/years. It can be seen that the relatively low overall accuracy of 0.824 for the growing season of 2016-2017 was mainly attributed to the errors of commission for deciduous forest (38.2\%), built-up land (19.5\%) and other crops (18.8\%). More detailed confusion matrices for each land cover type are shown in Table S2. 


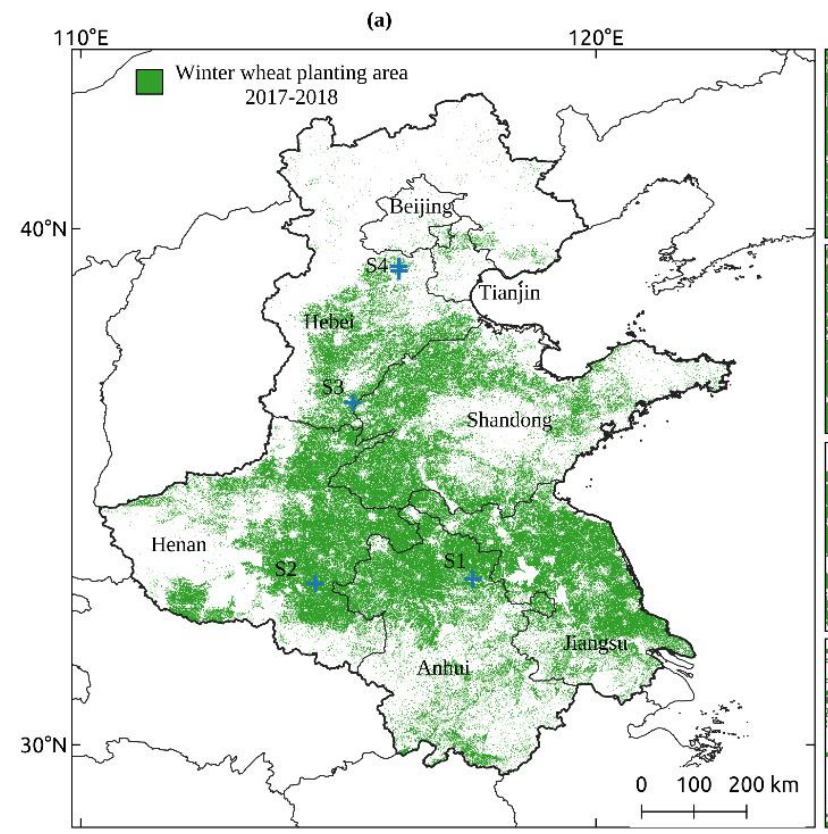

(b)

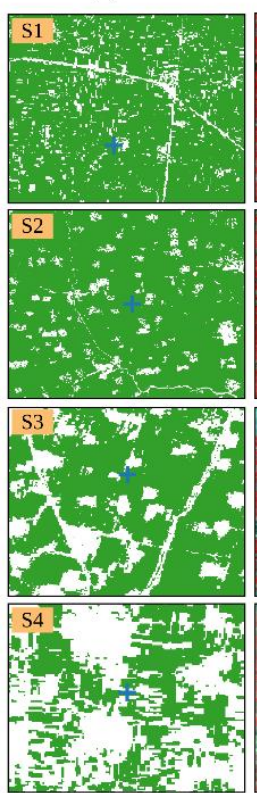

(c)

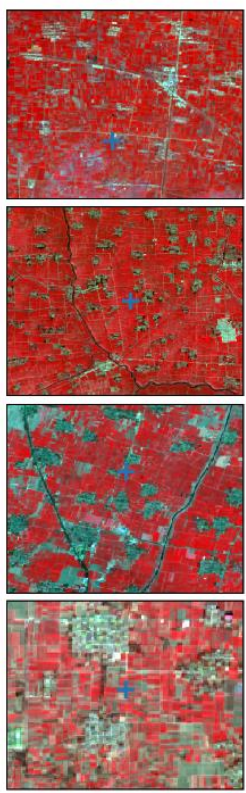

Figure 6. Map of winter wheat planting areas for the 2017-2018 cropping season (a,b) zoom-ins for the site S1, S2, S3 and S4, marked as blue crosses in (a). The false-color composites for visual interpretation (c) are based on average values of bands (SWIR1/ NIR/ Red) of Landsat-8 in March 2018.

Table 2. Confusion matrix of land cover validation based on the remaining sample pixels (Test 1) from GE, Sentinel-2 and Landsat. Overall accuracy and Kappa coefficients are provided.

\begin{tabular}{ccccc}
\hline \multirow{2}{*}{ Epodes } & Winter Wheat & Non-Winter Wheat & \multirow{2}{*}{ Overall Accuracy } & \multirow{2}{*}{ Kappa } \\
\cline { 2 - 3 } & User's Accuracy/Producer's Accuracy & User's Accuracy/Producer's Accuracy & & 0.915 \\
\hline $2014-2015$ & $0.979 / 0.996$ & $0.983 / 0.877$ & 0.942 & 0.874 \\
$2015-2016$ & $0.988 / 0.982$ & $0.940 / 0.933$ & 0.824 & 0.992 \\
$2016-2017$ & $0.930 / 0.979$ & $0.836 / 0.772$ & 0.917 & 0.891 \\
$2017-2018$ & $0.900 / 0.992$ & $0.868 / 0.768$ & 0.898 \\
$2018-2019$ & $0.958 / 0.977$ & $0.829 / 0.852$ & 0.856 \\
\hline
\end{tabular}

\subsection{Spatio-Temporal Patterns of Landsat Based Winter Wheat Areas for 1999-2018}

While no significant trends in the total areal extent of winter wheat planting area are observed for the period of 2000-2019 (Figure 7a) with an average increase of $1.42 \times 10^{6}$ ha in comparison to the winter wheat planted in the year of 2000, significant increase in winter wheat planting areas are observed in the Hebei and Shandong provinces $(p<0.05)$

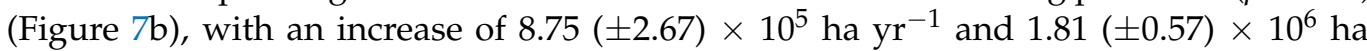
$\mathrm{yr}^{-1}$, respectively. It is noted that area uncertainties exist during the seasons of 1999-2000, 2002-2003, 2005-2007, 2009-2010 and 2015-2016 with an averaged area of $8.7 \times 10^{6}$ ha having no observations in NCP (Figure 7a). These periods, therefore, are not included in the calculation of the trend analysis. Further, we detect the frequency of winter wheat planting for the observed periods, showing a distinct higher frequency of winter wheat planting in eastern Henan, northern Anhui, southern Hebei, western Shandong and the most area in the northern of the Yangtse River in Jiangsu province (Figure 7c). Moreover, $1.02 \times 10^{7}$ ha (occupying $\sim 18 \%$ of the area where winter wheat is encountered during 1999-2019, i.e., frequency of winter wheat planted areas $>0$ ) of the study areas are observed always as winter wheat (Figure S5). Finally, we analyzed changes in winter wheat planting areas (see Section 2.2.4.) during 1999-2019 (Figure 7d) and found that 44\% of the area is characterized by the class denoted stable, whereas $29 \%$ of the area showed a gain and $27 \%$ a loss in winter wheat planting areas. 

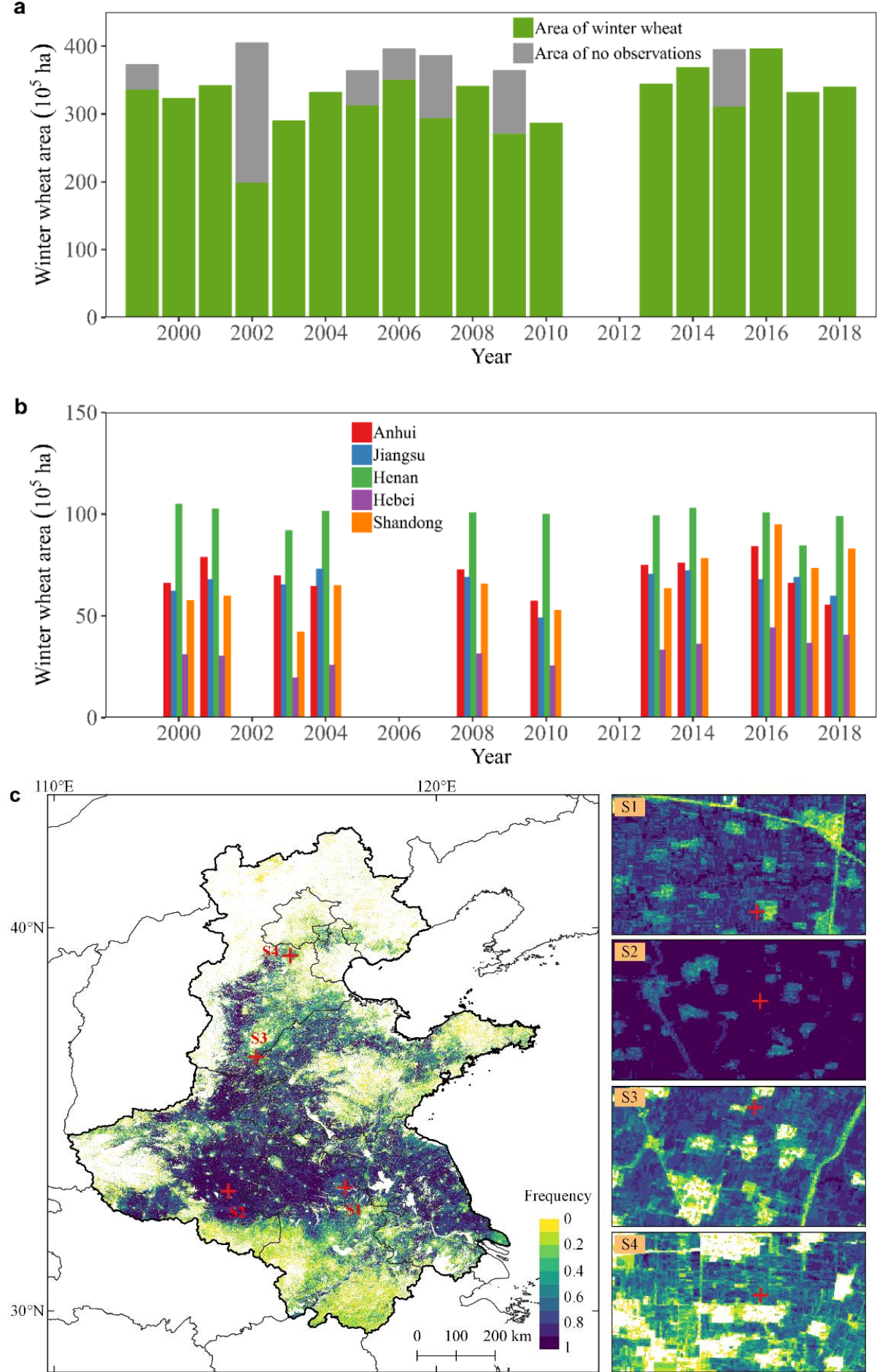

Figure 7. Cont. 

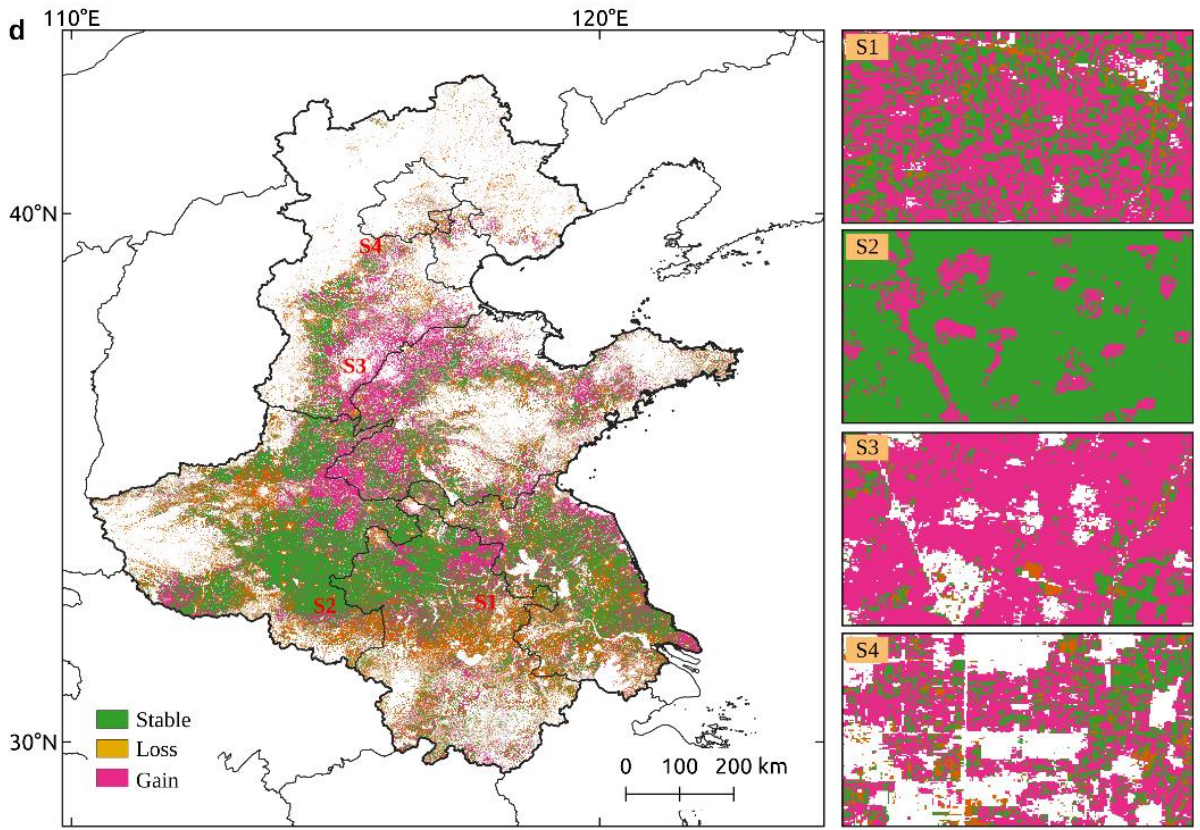

Figure 7. Dynamics and frequency of winter wheat planting areas. (a) The dynamics in the extent of winter wheat planting areas for 2000-2019 based on Landsat for the entire study area and (b) at the province level (excluding Beijing and Tianjin). Uncertainty is estimated from the unobserved component of the maximum extent in (a) and the true winter wheat planting area is within this range. These years are omitted from (b) due to the high uncertainty for some provinces. (c) The frequency of winter wheat planted during and (d) classes of stable, gain and loss of winter wheat areas for the full period of analysis.

\section{Discussion}

\subsection{Landsat Images for Phenology-Based Winter Wheat Planting Area Mapping}

We developed an approach using freely available time series data of Landsat imagery to reconstruct the dynamics of winter wheat planting areas in China at a spatial resolution of $30 \mathrm{~m}$ dating back to 1999. The results thereby advance the monitoring of winter wheat from MODIS 250-1000 $\mathrm{m}$ to $30 \mathrm{~m}$ spatial resolution [17,27]. As wheat growing in China is characterized by a high cropland fragmentation from the small and patchy nature of fields, the use of coarser-resolution MODIS data $(250 \mathrm{~m})$ includes considerable uncertainties. Satellite data of even finer spatial resolution with the ability to resolve temporal dynamics in seasonal spectral signatures, such as Sentinel-2 MSI $(10 \mathrm{~m})$, is promising to further improve mapping of winter wheat over such fragmented croplands, which however is limited to the mapping of recent years (since the launch of the Sentinel-2 A in June 2015). Four features that are important for the high-quality results are: (I) The spatial resolution $(30 \mathrm{~m})$ benefits the mapping of winter wheat in areas characterized by smallholder agriculture and heterogeneous landscape structures. (II) GEE, as a cloud computing platform, enables the means for fast data preprocessing and computation of massive amounts of Landsat scenes (28,826 Landsat images used in this study). (III) The use of phenological features derived from Landsat time series during growing seasons (as compared to the use of a single scene) was helpful to distinguish winter wheat from other crop and land cover types. (IV) The sensitivity detection analysis to derive the optimal class ratio $(\beta=1.8)$ of the training sample pixels, which achieves a balance between user's accuracy and producer's accuracy, was used to reduce the bias that is brought about by the unbalance of the class distribution.

\subsection{Uncertainty in Winter Wheat Mapping}

While the accuracies of the image classifications were generally high, potential uncertainties can be associated with the applied data and algorithms. Although the combined use of Landsat TM/ETM+/OLI images delivers a reasonably dense time series, the availability 
of Landsat images during the period of 2011-2012 is low (Figures 1c and S1), resulting in larger uncertainties of the results of the area classified as wheat during this period as the low frequency of observations cause a failure when computing all the phenological metrics used for the RF classifier. Therefore, 2011-2012 were omitted from the classification results reported, while for other years $(1999,2002,2005-2007,2009$ and 2015) uncertainty is estimated from the unobserved component of the maximum extent of wheat planting (Figure $7 \mathrm{a}, \mathrm{b}$ ). Reducing uncertainties in relation to production of historical reference data for the image classification is common challenge, but the use of historical VHR data in GE provides a valuable complementary data source to the use of Sentinel-2 and Landsat imagery. Uncertainties in the training/validation workflow due to possible Landsat coregistration errors is expected to be minimal due to the use of the Level-1TP (Precision and Terrain Correction) product in the wheat growing areas that are mostly flat areas. Furthermore, other uncertainties may exist in the design of the study: The phenology of winter wheat may have shifted due to global warming over the long time series. Applying different dates for Phase III and Phase IV calculations north and south of 34.57N latitude (due to differences in phenology) inevitably introduces the risk of creating artefacts in the classification output. Yet, no border effect could be observed. Finally, intra-class variability caused by field conditions and agricultural practices was not considered here [26].

We compared the winter wheat map $\left(3.32 \times 10^{7}\right.$ ha) developed in this study with the recently published winter wheat maps in the season of 2017-2018, with $3.73 \times 10^{7}$ [31] and $2.07 \times 10^{7}$ ha [32] (Figure 8). While the overall area estimate of our classification matches the area estimate of in Figure 8a relatively well, the spatially explicit mapping comparison show a $68 \%$ and $53 \%$ match of the winter wheat areas mapped in the two studies as compared to the winter wheat map developed here. Whereas our study generally maps less areas as winter wheat as compared to ref [31] (orange areas in Figure 8a), it is clear that our study maps considerably larger areas of winter wheat than ref [32] (pink areas in Figure 8b). This suggests that uncertainties of winter wheat maps are impacted by the differences in remote sensing data source and methods used.

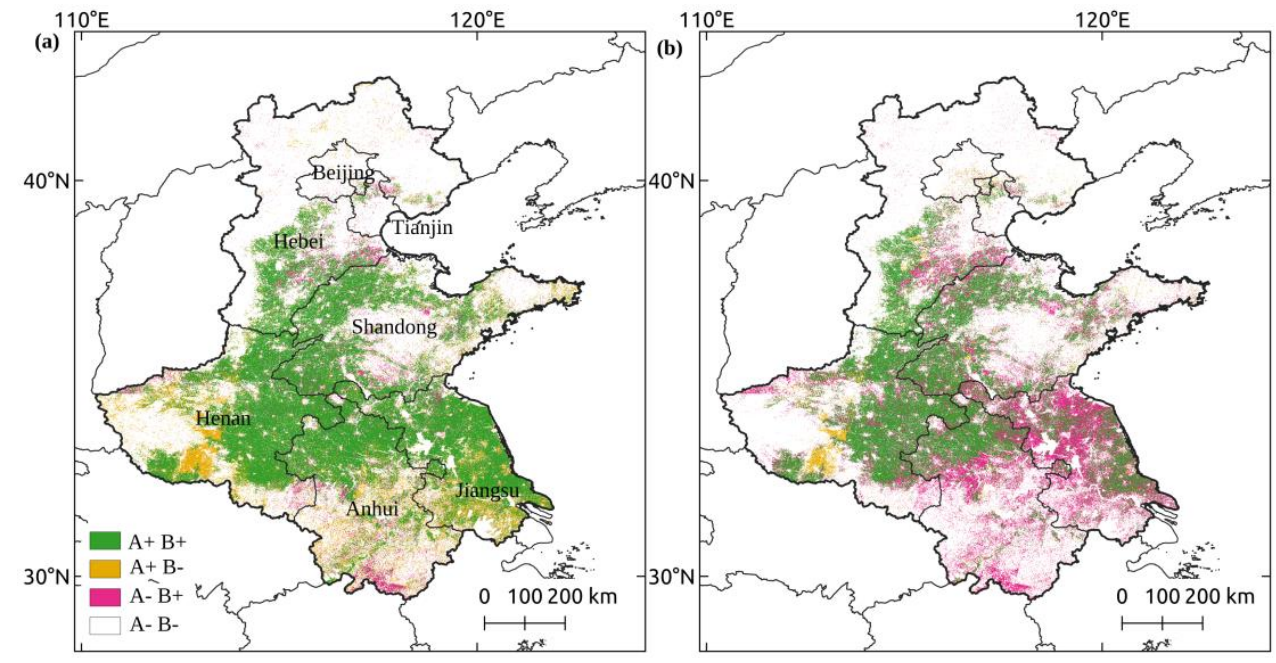

Figure 8. Comparison of the developed winter wheat mapping with the recent published mapping of winter wheat in 2007-2018. (a) Comparison with the result of ref [31]; (b) Comparison with the result of ref. [32]. A+B+ denotes both studies agree on the winter wheat mapping, $\mathrm{A}+\mathrm{B}-$ denotes winter wheat mapped in the cited study but not in our study, $\mathrm{A}-\mathrm{B}+$ denotes winter wheat mapped in our study but not in the cited study, A-B-denotes that winter wheat are not mapped in any of the studies. The corresponding winter wheat maps are shown in Supplementary (Figure S6).

\subsection{Dynamics of Winter Wheat}

An increase of winter wheat, on average, $1.42 \times 10^{6}$ ha in the entire NCP region, was observed in comparison to the year 2000 and significant increases were observed in the Hebei and Shandong provinces. Surprisingly, our findings contrast with other studies, 
which indicated that rapid economic development and urbanization in China resulted in the reduction of arable land in China available for agriculture/winter wheat production [38]. China experienced dramatic economic growth during recent decades, with a strong impact on livelihood strategies with many people moving from rural regions to cities, which has caused widespread urbanization and urban expansion [43]. This phenomenon has been particularly pronounced in NCP that includes the Jingjinji and Yangtze river delta urban agglomeration having the highest density of human population and the fastest rate of urban expansion in China [44]. Therefore, on the one hand, urbanization results in the loss of cultivated cropland due to urban sprawl [38]. On the other hand, urbanization may also have influenced cropping systems by increasing/decreasing winter wheat planting areas at the expense of other crop types. As urbanization can lead to a shift in cropping systems, for instance, increasingly more farmers plant market-driven crop species to optimize the household income [45]. Hence, in such circumstances, the winter wheat planting areas can be sustained and show an increasing tendency $\left(3.32( \pm 0.25) \times 10^{7} \mathrm{ha}\right)$ characterized even by a significant increase in some provinces (Hebei and Shandong). This study thereby provides a quantification supporting the important role of winter wheat for sustaining food security in China and that the high-quality arable land of NCP is being protected for agricultural use.

Climate change leads to an increase in the frequency of extreme weather events [46], which would pose a severe challenge for cropping systems in NCP. As winter wheat has a long growing season that spans autumn, winter and spring, it is sensitive to a changing climate, in particular increased temperature [47]. This may potentially lead to a change in winter wheat planting due to an adaption to ongoing climate change. In fact, heat stress can severely affect the wheat's growing season and yield [48], so farmers would be forced to change the future cropping types to plant crop types having a higher resilience to warming in order to mitigate economic losses. The availability of water (rainfall pattern, river runoff, irrigation) could be another factor controlling changes in winter wheat planting and the cropping systems [49]. Although suffering from these different adverse impacts of climate change and water availability, this study suggests that winter wheat planting is steadily increasing in the NCP, mitigating the increased demand from a rapidly growing population and reducing the dependency on grain import.

\subsection{Implication and Future Development of Winter Wheat Mapping}

Our study demonstrated the possibility of mapping winter wheat planting areas and tracking its dynamics using Landsat data in China, showing the potential to be applied at a global scale. The study contributes to remote sensing-based monitoring of wheat production, forming an important improved basis for global food security programs, and helps to explain the agriculture dominated greening Earth [50] and may also contribute to the understanding of the decline in terrestrial water storage in NCP [51]. Moreover, our study can be used as inspiration for developing workflows for winter wheat mapping in other major wheat breadbaskets of the world, such as smallholder farming systems in India, and the more mechanized large-scale production systems of European countries and Russia. While a finer-resolution of, e.g., Sentinel-2-based winter wheat mapping is a logical next step, the extensively temporal span of Landsat based mapping dating back to the 1980s is unmatched. This work was faced by the challenge of the uneven temporal Landsat data coverage. Yet, from the approach of forming epochs, high accuracy of the wheat mapping was achieved throughout the period of analysis. The limited Landsat data availability prior to the turn of the new millennium did not allow for a robust assessment following the epoch methodology taken here. The increase in winter wheat planting areas during recent decades, seemingly associated with a decline in areas under agriculture [38], suggests changed cropping systems, which should be further studied. 


\section{Conclusions}

An approach for mapping of winter wheat planting area at $30 \mathrm{~m}$ spatial resolution was developed for the breadbasket of China from 1999 to 2019, using Landsat imagery time series. We observed an increase in winter wheat of $1.42 \times 10^{6}$ ha in the entire area of the NCP in comparison to the year 2000, with a significant increase in the Shandong and Hebei provinces $(p<0.05)$. In the context of an overall decrease in cropland areas and adverse impacts from climate change and water availability, these results suggest that cropping systems in NCP sustain winter wheat planting to meet the increased food demand from an increasing population. The results underline the value and potential for Landsat images for long-term monitoring of winter wheat in areas characterized by small agricultural plot sizes and efficiently quantify the past and ongoing changes in wheat cropping systems in one of the most densely populated regions of China. The approach developed has the potential to be reproducible elsewhere and/or at the global scale, as winter wheat generally has distinct temporal phenological spectral features as compared to other crop-types, and the entire Landsat archive is accessible via cloud-based computing services such as the one provided by GEE.

Supplementary Materials: The following are available online at https:/ /www.mdpi.com/2072-4 292/13/6/1170/s1, Figure S1. The number of available observations based on Landsat images per growing season of winter wheat during 1999-2019; Figure S2. Winter wheat photos taken during field campaign in April, 2019; Figure S3. Illustration of temporal profiles of other crop types (Location: $116.66089 \mathrm{E}, 33.3537 \mathrm{~N}$ ); Figure S4. Temporal EVI of (a) winter wheat and (b) other land cover types in the study area; Figure S5. Map of stable and changed winter wheat planting areas for the period 1999-2019; Figure S6. Maps of winter wheat planting areas for the period 2017-2018 based on the reference studies [1,2]; Table S1. Accuracy error matrix. Table S2. Confusion matrix of land cover validation based on the remaining sample pixels (Test 1) from GE, Sentinel-2 and Landsat.

Author Contributions: Conceptualization, W.Z., M.B., A.V.P., Z.L. and C.L.; methodology, W.Z.; software, W.Z.; validation, W.Z., C.L.; formal analysis, W.Z.; investigation, W.Z.; resources, W.Z.; data curation, W.Z.; writing—original draft preparation, W.Z.; writing—review and editing, W.Z.; supervision, C.L., R.F.; project administration, C.L.; funding acquisition, C.L. All authors have read and agreed to the published version of the manuscript.

Funding: National Postdoctoral Program for Innovative Talents (BX20190154,) and the National Natural Science Foundation of China (grant number: 42001349), Shandong Province Natural Science Foundation (No. ZR2016DB06). M.B. is supported by the AXA postdoctoral research grant. A.V.P. is supported by DFF-Danish ERC Support Program (grant number: 116491, 9127-00001B). R.F. acknowledges support by the Villum Foundation through the project 'Deep Learning and Remote Sensing for Unlocking Global Ecosystem Resource Dynamics' (DeReEco).

Data Availability Statement: Not applicable.

Acknowledgments: We thank Huan Zhang, Wangxin Yang, Lei Han for taking winter wheat sample from the field work.

Conflicts of Interest: The authors declare no conflict of interest.

\section{References}

1. Tilman, D.; Balzer, C.; Hill, J.; Befort, B.L. Global food demand and the sustainable intensification of agriculture. Proc. Natl. Acad. Sci. USA 2011, 108, 20260-20264. [CrossRef] [PubMed]

2. Song, X.-P.; Hansen, M.C.; Stehman, S.V.; Potapov, P.V.; Tyukavina, A.; Vermote, E.F.; Townshend, J.R. Global land change from 1982 to 2016. Nat. Cell Biol. 2018, 560, 639-643. [CrossRef] [PubMed]

3. Foley, J.A.; DeFries, R.; Asner, G.P.; Barford, C.; Bonan, G.; Carpenter, S.R.; Chapin, F.S.; Coe, M.T.; Daily, G.C.; Gibbs, H.K.; et al. Global consequences of land use. Science 2005, 309, 570-574. [CrossRef] [PubMed]

4. Trnka, M.; Rötter, R.P.; Ruiz-Ramos, M.; Kersebaum, K.C.; Olesen, J.E.; Žalud, Z.; Semenov, M.A. Adverse weather conditions for European wheat production will become more frequent with climate change. Nat. Clim. Chang. 2014, 4, 637-643. [CrossRef]

5. United States Department of Agriculture National Agricultural Statistics Service. Available online: https:/ /www.statista.com/ statistics/267268/production-of-wheat-worldwide-since-1990/ (accessed on 10 December 2020). 
6. Ray, D.K.; Ramankutty, N.; Mueller, N.D.; West, P.C.; Foley, J.A. Recent patterns of crop yield growth and stagnation. Nat. Commun. 2012, 3, 1293. [CrossRef] [PubMed]

7. Atzberger, C. Advances in remote sensing of agriculture: Context description, existing operational monitoring systems and major information needs. Remote Sens. 2013, 5, 949-981. [CrossRef]

8. $\quad$ Fritz, S.; See, L.; Bayas, J.C.L.; Waldner, F.; Jacques, D.; Becker-Reshef, I.; Whitcraft, A.; Baruth, B.; Bonifacio, R.; Crutchfield, J.; et al. A comparison of global agricultural monitoring systems and current gaps. Agric. Syst. 2019, 168, 258-272. [CrossRef]

9. Rapsomanikis, G. The Economic Lives of Smallholder Farmers: An Analysis Based on Household Data from Nine Countries; Food and Agriculture Organization of the United Nations: Rome, Italy, 2015.

10. Xu, M.; He, C.; Liu, Z.; Dou, Y. How did urban land expand in China between 1992 and 2015? A multi-scale landscape analysis. PLoS ONE 2016, 11, e0154839. [CrossRef]

11. Liu, Z.; Yang, P.; Wu, W.; You, L. Spatiotemporal changes of cropping structure in China during 1980-2011. J. Geogr. Sci. 2018, 28, 1659-1671. [CrossRef]

12. Liu, B.; Liu, L.; Tian, L.; Cao, W.; Zhu, Y.; Asseng, S. Post-heading heat stress and yield impact in winter wheat of China. Glob. Chang. Biol. 2014, 20, 372-381. [CrossRef]

13. Ortiz, R.; Sayre, K.D.; Govaerts, B.; Gupta, R.; Subbarao, G.; Ban, T.; Hodson, D.; Dixon, J.M.; Ortiz-Monasterio, J.I.; Reynolds, M. Climate change: Can wheat beat the heat? Agric. Ecosyst. Environ. 2008, 126, 46-58. [CrossRef]

14. Chen, J.; Chen, J.; Liao, A.; Cao, X.; Chen, L.; Chen, X. Global land cover mapping at $30 \mathrm{~m}$ resolution: A POK-based operational approach. ISPRS J. Photogramm. Remote Sens. 2014, 103, 7-27. [CrossRef]

15. Gong, P.; Liu, H.; Zhang, M.; Li, C.; Wang, J.; Huang, H.; Clinton, N.; Ji, L.; Li, W.; Bai, Y.; et al. Stable classification with limited sample: Transferring a 30-m resolution sample set collected in 2015 to mapping 10-m resolution global land cover in 2017. Sci. Bull. 2019, 64, 370-373. [CrossRef]

16. Xu, F.; Li, Z.; Zhang, S.; Huang, N.; Quan, Z.; Zhang, W. Mapping winter wheat with combinations of temporally aggregated Sentinel-2 and Landsat-8 data in Shan-dong Province, China. Remote Sens. 2020, 12, 2065. [CrossRef]

17. Pan, Y.; Li, L.; Zhang, J.; Liang, S.; Zhu, X.; Sulla-Menashe, D. Winter wheat area estimation from MODIS-EVI time series data using the Crop Proportion Phenology Index. Remote Sens. Environ. 2012, 119, 232-242. [CrossRef]

18. Cai, Y.; Guan, K.; Peng, J.; Wang, S.; Seifert, C.; Wardlow, B.; Li, Z. A high-performance and in-season classification system of field-level crop types using time-series Landsat data and a machine learning approach. Remote Sens. Environ. 2018, $210,35-47$. [CrossRef]

19. Daughtry, C.; Hunt, E.; Doraiswamy, P.; McMurtrey, J.; Russ, A. Remote sensing of crop residue cover and soil tillage intensity. Soil Tillage Res. 2006, 91, 101-108. [CrossRef]

20. Paloscia, S.; Pettinato, S.; Santi, E.; Notarnicola, C.; Pasolli, L.; Reppucci, A.J.R.S.O.E. Soil moisture mapping using Sentinel-1 imag-es: Algorithm and preliminary validation. Remote Sens. Environ. 2013, 134, 234-248. [CrossRef]

21. Wang, S.; Azzari, G.; Lobell, D.B. Crop type mapping without field-level labels: Random forest transfer and unsuper-vised clustering techniques. Remote Sens. Environ. 2019, 222, 303-317. [CrossRef]

22. Wei, M.; Qiao, B.; Zhao, J.; Zuo, X. The area extraction of winter wheat in mixed planting area based on Sentinel-2 a re-mote sensing satellite images. Int. J. Parallel Emergent Distrib. Syst. 2020, 35, 297-308. [CrossRef]

23. Sui, X.; Zhang, X.; Li, S.; Zhu, Z.; Ming, B.; Sun, X. Extracting winter wheat planting area based on cropping system with remote sensing. Lect. Notes Control Inf. Sci. 2011, 345, 691-699. [CrossRef]

24. Ozdogan, M.; Woodcock, C.E. Resolution dependent errors in remote sensing of cultivated areas. Remote Sens. Environ. 2006, 103, 203-217. [CrossRef]

25. Löw, F.; Prishchepov, A.V.; Waldner, F.; Dubovyk, O.; Akramkhanov, A.; Biradar, C.; Lamers, J.P.A. Mapping cropland abandonment in the Aral Sea Basin with MODIS time series. Remote Sens. 2018, 10, 159. [CrossRef]

26. Yang, Y.; Tao, B.; Ren, W.; Zourarakis, D.P.; El Masri, B.; Sun, Z.; Tian, Q. An improved approach considering intraclass variability for mapping winter wheat using multitemporal MODIS EVI images. Remote Sens. 2019, 11, 1191. [CrossRef]

27. Qiu, B.; Luo, Y.; Tang, Z.; Chen, C.; Lu, D.; Huang, H.; Chen, Y.; Chen, N.; Xu, W. Winter wheat mapping combining variations before and after estimated heading dates. ISPRS J. Photogramm. Remote Sens. 2017, 123, 35-46. [CrossRef]

28. Lhermitte, S.; Verbesselt, J.; Verstraeten, W.W.; Coppin, P. A comparison of time series similarity measures for classifi-cation and change detection of ecosystem dynamics. Remote Sens. Environ. 2011, 115, 3129-3152. [CrossRef]

29. Guerschman, J.P.; Paruelo, J.M.; Di Bella, C.; Giallorenzi, M.C.; Pacin, F. Land cover classification in the Argentine Pampas using multi-temporal Landsat TM data. Int. J. Remote Sens. 2003, 24, 3381-3402. [CrossRef]

30. Belgiu, M.; Csillik, O. Sentinel-2 cropland mapping using pixel-based and object-based time-weighted dynamic time warping analysis. Remote Sens. Environ. 2018, 204, 509-523. [CrossRef]

31. Dong, Q.; Chen, X.; Chen, J.; Zhang, C.; Liu, L.; Cao, X.; Zang, Y.; Zhu, X.; Cui, X. Mapping winter wheat in North China using Sentinel 2A/B Data: A method based on Phenology-Time Weighted Dynamic Time Warping. Remote Sens. 2020, $12,1274$. [CrossRef]

32. Dong, J.; Fu, Y.; Wang, J.; Tian, H.; Fu, S.; Niu, Z.; Han, W.; Zheng, Y.; Huang, J.; Yuan, W. Early-season mapping of winter wheat in China based on Landsat and Sentinel images. Earth Syst. Sci. Data 2020, 12, 3081-3095. [CrossRef]

33. Zhong, L.; Hu, L.; Zhou, H.; Tao, X. Deep learning based winter wheat mapping using statistical data as ground refer-ences in Kansas and northern Texas, US. Remote Sens. Environ. 2019, 233, 111411. [CrossRef] 
34. Belgiu, M.; Drăguț, L. Random forest in remote sensing: A review of applications and future directions. ISPRS J. Photogramm. Remote Sens. 2016, 114, 24-31. [CrossRef]

35. Stumpf, A.; Kerle, N. Object-oriented mapping of landslides using Random Forests. Remote Sens. Environ. 2011, 115, 2564-2577. [CrossRef]

36. Chen, T.-H.K.; Prishchepov, A.V.; Fensholt, R.; Sabel, C.E. Detecting and monitoring long-term landslides in urban-ized areas with nighttime light data and multi-seasonal Landsat imagery across Taiwan from 1998 to 2017. Remote Sens. Environ. 2019, 225, 317-327. [CrossRef]

37. Gorelick, N.; Hancher, M.; Dixon, M.; Ilyushchenko, S.; Thau, D.; Moore, R. Google Earth Engine: Planetary-scale geospa-tial analysis for everyone. Remote Sens. Environ. 2017, 202, 18-27. [CrossRef]

38. Liu, F.; Zhang, Z.; Zhao, X.; Wang, X.; Zuo, L.; Wen, Q.; Yi, L.; Xu, J.; Hu, S.; Liu, B. Chinese cropland losses due to urban expansion in the past four decades. Sci. Total. Environ. 2019, 650, 847-857. [CrossRef] [PubMed]

39. Deng, X.; Huang, J.; Rozelle, S.; Zhang, J.; Li, Z. Impact of urbanization on cultivated land changes in China. Land Use Policy 2015, 45, 1-7. [CrossRef]

40. Foga, S.; Scaramuzza, P.L.; Guo, S.; Zhu, Z.; Dilley, R.D.; Beckmann, T.; Schmidt, G.L.; Dwyer, J.L.; Hughes, M.J.; Laue, B. Cloud detection algorithm comparison and validation for operational Landsat data products. Remote Sens. Environ. 2017, 194, 379-390. [CrossRef]

41. Olofsson, P.; Foody, G.M.; Herold, M.; Stehman, S.V.; Woodcock, C.E.; Wulder, M.A. Good practices for estimating area and assessing accuracy of land change. Remote Sens. Environ. 2014, 148, 42-57. [CrossRef]

42. Pekel, J.-F.; Cottam, A.; Gorelick, N.; Belward, A.S. High-resolution mapping of global surface water and its long-term changes. Nature 2016, 540, 418-422. [CrossRef] [PubMed]

43. Schneider, A.; Mertes, C.M. Expansion and growth in Chinese cities, 1978-2010. Environ. Res. Lett. 2014, 9, 024008. [CrossRef]

44. Haas, J.; Ban, Y. Urban growth and environmental impacts in Jing-Jin-Ji, the Yangtze, River Delta and the Pearl River Delta. Int. J. Appl. Earth Obs. Geoinform. 2014, 30, 42-55. [CrossRef]

45. Yuan, W.; Liu, S.; Liu, W.; Zhao, S.; Dong, W.; Tao, F. Opportunistic market-driven regional shifts of cropping practices reduce food production capacity of China. Earth's Future 2018, 6, 634-642. [CrossRef]

46. Sun, Y.; Zhang, X.; Zwiers, F.W.; Song, L.; Wan, H.; Hu, T.; Yin, H.; Ren, G. Rapid increase in the risk of extreme summer heat in Eastern China. Nat. Clim. Chang. 2014, 4, 1082-1085. [CrossRef]

47. Tao, F.; Zhang, Z.; Xiao, D.; Zhang, S.; Rötter, R.P.; Shi, W.; Liu, Y.; Wang, M.; Liu, F.; Zhang, H. Responses of wheat growth and yield to climate change in different climate zones of China, 1981-2009. Agric. For. Meteorol. 2014, 189-190, 91-104. [CrossRef]

48. Tao, F.; Zhang, Z.; Zhang, S.; Rötter, R.P. Heat stress impacts on wheat growth and yield were reduced in the Huang-Huai-Hai Plain of China in the past three decades. Eur. J. Agron. 2015, 71, 44-52. [CrossRef]

49. Wu, X.; Qi, Y.; Shen, Y.; Yang, W.; Zhang, Y.; Kondoh, A. Change of winter wheat planting area and its impacts on groundwater depletion in the North China Plain. J. Geogr. Sci. 2019, 29, 891-908. [CrossRef]

50. Chen, C.; Park, T.; Wang, X.; Piao, S.; Xu, B.; Chaturvedi, R.K.; Fuchs, R.; Brovkin, V.; Ciais, P.; Fensholt, R.; et al. China and India lead in greening of the world through land-use management. Nat. Sustain. 2019, 2, 122-129. [CrossRef] [PubMed]

51. Rodell, M.; Famiglietti, J.S.; Wiese, D.N.; Reager, J.T.; Beaudoing, H.K.; Landerer, F.W.; Lo, M.-H. Emerging trends in global freshwater availability. Nat. Cell Biol. 2018, 557, 651-659. [CrossRef] 